14,15

\title{
$S$-образные вольт-амперные характеристики композитных пленок на основе полимеров с частицами графена и оксида графена
}

\author{
() П.С. Крылов ${ }^{1}$, А.С. Берестенников ${ }^{1}$, С.А. Фефелов ${ }^{1}$, А.С. Комолов ${ }^{2}$, А.Н. Алешин ${ }^{1,}$ \\ ${ }^{1}$ Физико-технический институт им. А.Ф. Иофрфе РАН, \\ Санкт-Петербург, Россия \\ ${ }^{2}$ Санкт-Петербургский государственный университет, \\ Санкт-Петербург, Россия \\ ฯ E-mail: aleshin@transport.ioffe.ru
}

(Поступила в Редакцию 23 мая 2016 г.)

\begin{abstract}
Исследованы эффекты резистивного переключения в композитных пленках на основе полифункциональных полимеров: производных карбазола (PVK), флуорена (PFD), поливинилхлорида (PVC), а также частиц графена $(\mathrm{Gr})$ и оксида графена $(\mathrm{GO})$, концентрация которых в матрице полимера составляла $\sim 1-3 \mathrm{wt} . \%$, что соответствует порогу перколяции в таких системах. Диагностика атомного состава исследованных композитов, проводившаяся с помощью рентгеновской фотоэлектронной спектроскопии, показала, что степень окисления Gr в GO составляет 9-10\%. Установлено, что в структурах Au/PVK(PFD;PVC): Gr(GO)/ITO/PET (ITO - indium tin oxide, PET - poly(ethylene terephthalate)) при подаче импульса напряжения наблюдается резкий скачок проводимости, характеризующийся $S$-образными вольт-амперными характеристиками при наличии гистерезиса, при этом время переключения составляет $t \sim 1-30 \mu \mathrm{s}$. Наблюдаемые эффекты объяснены влиянием окислительно-восстановительных реакций в частицах $\mathrm{Gr}$ и GO, заключенных в матрицу полимера, при дополнительном влиянии термомеханических свойств полимерной составляющей композита.

Работа выполнена при частичной финансовой поддержке Программы фундаментальных исследований Президиума РАН П8 (направление „Фундаментальные принципы создания и исследования новых веществ и материалов для молекулярной электроники и спинтроники“), гранта РФФИ № 15-02-01897, а также гранта СПбГУ 11.38.219.2014.
\end{abstract}

Использовалось оборудование научного парка СПбГУ „Физические методы исследования поверхности“.

\section{1. Введение}

Композитные (органика-неорганика) материалы вызывают большой интерес в связи с перспективами их применения в качестве энергонезависимых запоминающих устройств, обладающих высоким быстродействием, большой плотностью хранения информации, малым энергопотреблением и низкой себестоимостью [1]. В таких композитных материалах на основе неорганических наночастиц, встроенных в полимерную матрицу, наблюдаются эффекты резистивного переключения, проявляющиеся в резком переходе образцов из низкопроводящего (НП) в высокопроводящее (ВП) состояние при подаче электрического смещения на электроды $[2,3]$. В последние годы наряду с композитами на основе полимеров и неорганических наночастиц большое внимание уделяется перспективным композитным материалам на основе частиц графена (Gr) и оксида графена (GO), внедренных в матрицу полупроводниковых и диэлектрических полимеров, так как Gr и GO являются эффективными средами для накопления носителей заряда $[3,4]$. В наших предыдущих работах были исследованы эффекты переключения проводимости на постоянном токе в композитных структурах на основе полифункциональных полимеров: производных карбазола (PVK) и флуорена (PFD), содержащих частицы Gr и GO при их концентрациях в полимерной матрице $\sim 1-3 w t . \%$, а также рассмотрена окислительно-восстановительная природа этих эффектов [5,6]. Было показано, что полевые транзисторы на основе композитных пленок PVK: GO также демонстрируют эффекты переключения тока и обладают значительно большей (более чем в $10^{9}$ раз) подвижностью носителей заряда по сравнению с транзисторными структурами на основе чистых полимерных пленок PVK [7]. Важно отметить, что характер окислительновосстановительных реакций частиц Gr и GO, а следовательно, и механизм эффекта переключения зависят от содержания кислорода в исходных компонентах. В связи с этим необходимо контролировать содержание кислорода в GO, так как содержание карбоксильных и карбонильных терминальных групп в GO существенно зависит от термической и химической обработки [8]. С другой стороны, динамика и механизм эффекта переключения в импульсном режиме в композитных структурах на основе полимеров с частицами $\mathrm{Gr}$ и GO до сих пор исследованы недостаточно полно.

Целью настоящей работы является исследование эффекта резистивного переключения в тонких композитных пленках, входящих в сандвич-структуры вида $\mathrm{Au} / \mathrm{PVK}(\mathrm{PFD} ; \mathrm{PVC}): \mathrm{Gr}(\mathrm{GO}) / \mathrm{ITO} / \mathrm{PET}$ (PVC — поливинилхлорид, ITO - indium tin oxide, PET - poly(ethylene terephthalate)) при подаче на них импульса напряжения. Наблюдаемый скачок проводимости сопровождается появлением $S$-образных вольт-амперных характеристик (BAX) при наличии гистерезиса. Время переключения в таких структурах составляет $t \sim 1-30 \mu$ s. Наблюдаемые 
эффекты связаны с особенностями термомеханических свойств полимера в композите, а также с процессами окислительно-восстановительных реакций частиц Gr и GO, заключенных в матрицу полимера.

\section{2. Объекты и методы исследования}

Исследовались электрические свойства композитных пленок на основе растворимых в органических растворителях полифункциональных полимеров: производных карбазола (poly (9-vinylcarbazole)) - PVK, $\left(\mathrm{C}_{14} \mathrm{H}_{11} \mathrm{~N}\right)_{n}$, молекулярная масса $M_{\omega} \sim 1.1 \cdot 10^{6}$, ширина запрещенной зоны $E_{g} \sim 3.6 \mathrm{eV}$; производных флуорена (poly (9,9-di- $n$-dodecylfluorenyl-2,7-diyl)) - PFD, $\left(\mathrm{C}_{31} \mathrm{H}_{44} \mathrm{~B}_{2} \mathrm{O}_{5}\right)_{n}, M_{\omega} \sim 5.18 \cdot 10^{2}, E_{g} \sim 3.36 \mathrm{eV}$; поливинилхлорида (polyvinyl chloride) $-\mathrm{PVC},\left(\mathrm{C}_{2} \mathrm{H}_{3} \mathrm{Cl}\right)_{n}$, $M_{\omega} \sim 4 \cdot 10^{4}-1.45 \cdot 10^{5}, E_{g} \sim 4.86 \mathrm{eV}$, а также встроенных в них частиц $\mathrm{Gr}$ (высокотемпературно восстановленный графен) и GO диаметром $\sim 200-300$ и $\sim 400-500 \mathrm{~nm}$ соответственно. Концентрация частиц $\mathrm{Gr}$ и $\mathrm{GO}$ в полимерной матрице варьировалась в пределах $1-3$ wt.\%, т. е. образцы композитных пленок находились на границе или ниже порога перколяции таких систем. Структуры молекул полимеров PVK, PFD и PVC приведены на рис. 1. PVK и PFD были приобретены в Sigma-Aldrich, а PVC - в ФГУП „ВНИИСВ“ (Тверь), полимеры использовались без дальнейшей обработки. Частицы Gr и GO были приобретены в ООО „АкКоЛаб“ (Москва) и также использовались в композитах без дополнительной модификации. В процессе изготовления образцов были приготовлены растворы полимеров PVK, PFD и PVC в хлороформе, в которые также были добавлены частицы Gr и GO. Растворы перемешивались ультразвуком (Bandelin Sonopuls HD 2070, $f \sim 20 \mathrm{kHz}$ ) в течение $5 \mathrm{~min}$. Полученные $20 \%$-ные растворы полимеров с частицами $\mathrm{Gr}$ и $\mathrm{GO}$ в хлороформе (концентрация частиц $\mathrm{Gr}$ и $\mathrm{GO}$ от $2-3 \mathrm{wt} . \%$ ) наносились методом центрифугирования при 2500-3200 rpm на гибкие РЕT-подложки с проводящим слоем ITO $\left(\operatorname{In}_{2} \mathrm{O}_{3} / \mathrm{SnO}_{2}\right.$, Sigma-Aldrich, поверхностное удельное сопротивление $\rho_{S} \sim 60 \Omega / \mathrm{cm}^{2}$ ) с последующим высушиванием при $80^{\circ} \mathrm{C}$ в течение $20 \mathrm{~min}$. Морфология и толщина полученных композитных слоев оценивались с помощью атомносилового микроскопа P47-Solver, при этом толщины слоев составляли $\sim 100-200 \mathrm{~nm}$. Диагностика атомного состава композитных пленок, в том числе диагностика содержания кислорода в GO, проводилась методом рентгеновской фотоэлектронной спектроскопии (XPS) на установке Escalab 250Xi (Thermo Fisher Scientific Inc.) в вакууме при давлении $10^{-7} \mathrm{~Pa}$. Для этих экспериментов были приготовлены пленки PVK (PFD, PVC), нанесенные на поверхность окисленного кремния, аналогичные используемым в структурах для измерений ВАХ. Для определения содержания кислорода в GO были приготовлены пленки GO на танталовой подложке путем осаждения из взвеси в толуоле в течение одной секунды после остановки ультразвукового размешивания.<smiles>CC(C)n1c2ccccc2c2ccccc21</smiles>

$a$

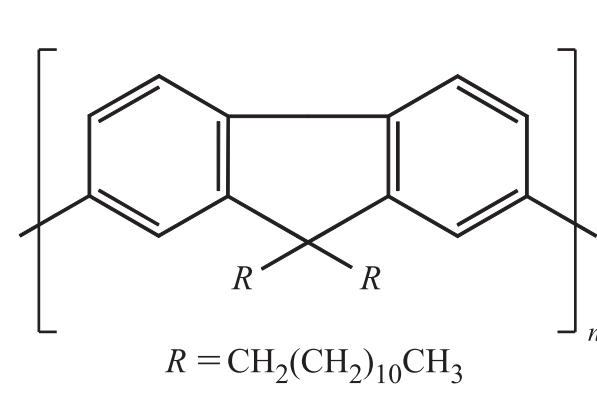

$b$<smiles>CC(C)(C)CC(Cl)C(C)(C)C</smiles>

c

Рис. 1. Структура молекул полимеров: $a-\mathrm{PVK}, b-\mathrm{PFD}$, $c-\mathrm{PVC}$.

BAX композитных пленок измерялись в импульсном режиме при $300 \mathrm{~K}$ на установке с генератором тока PCG10A. На образец и последовательно соединенное с ним сопротивление нагрузки с генератора подавалось импульсное напряжение. В качестве нижнего электрода образцов выступал слой ITO, в качестве верхнего золотой прижимной контакт площадью $S \sim 10^{-4} \mathrm{~cm}^{2}$. Импульс длительностью $2 \mathrm{~ms}$ имел треугольную форму, максимальное значение тока составило $100 \mu \mathrm{A}$, период тактовой частоты был выбран $4 \mu \mathrm{s}$. Измерение напряжения проводилось с помощью двухканального осциллографа PS500. Величина тока определялась по падению напряжения на нагрузке, а напряжение на образце как разница поданного напряжения $U_{0}$ и напряжения на нагрузке. Структура образцов и схема установки приведены на рис. 2 [9]. Исследование температурной зависимости проводимости композитных пленок осуществлялось двухзондовым методом на постоянном токе в диапазоне температур $70-300 \mathrm{~K}$ при напряжениях от -1.5 до $+1.5 \mathrm{~V}$ с использованием автоматизированной установки на основе пикоамперметра Keithley 6487 и оптического проточного азотного криостата со стабилизацией температуры OPTCRYO198.

\section{3. Результаты и обсуждение}

Диагностика атомного состава композитных пленок полимеров с частицами $\mathrm{Gr}(\mathrm{GO})$ проводилась с целью 


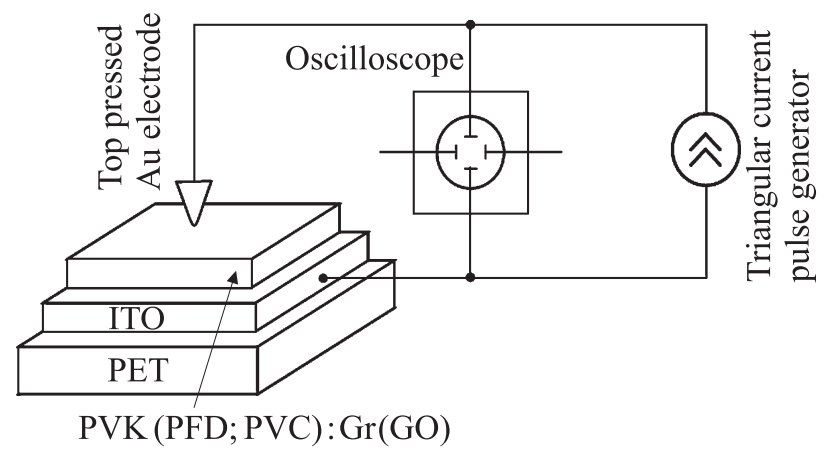

Рис. 2. Структура исследуемых образцов и схема установки по измерению ВАХ.

установления относительных концентраций основных атомных компонентов PVK (PFD, PVC). Для исследованных пленок полимеров результаты XPS-диагностики показали, что атомный состав образцов соответствует химическим формулам молекул, а результаты изучения состава пленок полимеров хорошо воспроизводимы. Так, для образцов PVK наблюдались основные максимумы $\mathrm{C}_{1 s}(284.5 \mathrm{eV}), \mathrm{O}_{1 s}(532 \mathrm{eV})$ и $\mathrm{N}_{1 s}(400 \mathrm{eV})$, при этом отношение концентраций атомов $\mathrm{C}: \mathrm{N}: \mathrm{O}$ составило $\sim 12: 1: 1$, что совпадает с составом образцов пленок PVK, изученных нами ранее [5-7]. При добавлении небольшого количества $(\sim 1-3 \mathrm{wt} . \%)$ частиц $\mathrm{Gr}$ и GO в состав исследованных композитов изначально не ожидалось значительного изменения относительных атомных концентраций по сравнению с результатами для однокомпонентных полимерных пленок. Для экспериментальной проверки степени окисления $\mathrm{Gr}$ в образцах GO были выбраны Та-подложки, так как тантал является термостойким, слабоокисляющимся металлом. В результате XPS-измерений образцов GO на Та-подложке, помещенных в вакуумную камеру без дополнительной очистки, были обнаружены максимумы $\mathrm{Ta}_{4 f}, \mathrm{C}_{1 s}$ и $\mathrm{O}_{1 s}$ (рис $3, a-c)$. После проведения нескольких циклов очистки образца методом бомбардировки ионами $\mathrm{Ar}^{+}$c энергией $3 \mathrm{keV}$ в течение $30 \mathrm{~s}$ было обнаружено изменение в спектре XPS на участках, характерных для максимумов $\mathrm{Ta}_{4 f}, \mathrm{C}_{1 s}$ и $\mathrm{O}_{1 s}$ (рис. $3, d-f$ ). Из литературных данных [10] известно, что парный максимум $\mathrm{Ta}_{4}$ в случае чистого Та имеет вершины при энергиях связи $21-24 \mathrm{eV}$, а в случае оксида тантала - при энергиях связи 26-29eV. В исследованных образцах до ионной очистки окисленная форма тантала преобладает над неокисленной (рис. 3,a). В результате очистки оксид тантала был удален, а максимум Та 4 принял вид, характерный для чистого Та (рис. $3, d$ ). Если пленка GO при осаждении из взвеси не сформировала сплошного покрытия на Та-подложке, то в результате ионной очистки различные атмосферные кислородсодержащие и углеродсодержащие загрязнения удалялись как с открытых участков поверхности Та, так и с поверхности пленки GO. Наблюдаемый в нашем случае максимум $\mathrm{C}_{1 s}$ расположен при значении энергии связи $284.5 \mathrm{eV}$ (рис. $3, b, e$ ), что хорошо согласуется с литературными данными для энергии связи атома углерода в $\mathrm{Gr}$ или в составе ароматических соединений $[8,11]$. С учетом чувствительности установки при регистрации XPS-сигнала [10], при определении положений максимумов $\mathrm{Ta}_{4 f}, \mathrm{C}_{1 s}$ и $\mathrm{O}_{1 s}$ для случая очищенного композитного образца отношение концентраций атомов Та: $\mathrm{C}: \mathrm{O}$ составило $2: 11: 1$. Таким образом, участки Та-подложки, не покрытые пленкой PVK: GO, нанесенной для XPS-исследований, занимают около $20 \%$ общей площади, а содержание кислорода в GO в случае PVK: GO составляет 9-10\%.

На рис. 4, $a, b$ представлены ВАХ композитных пленок PVK:Gr и PFD:Gr, PVC:GO при приложении импульс-
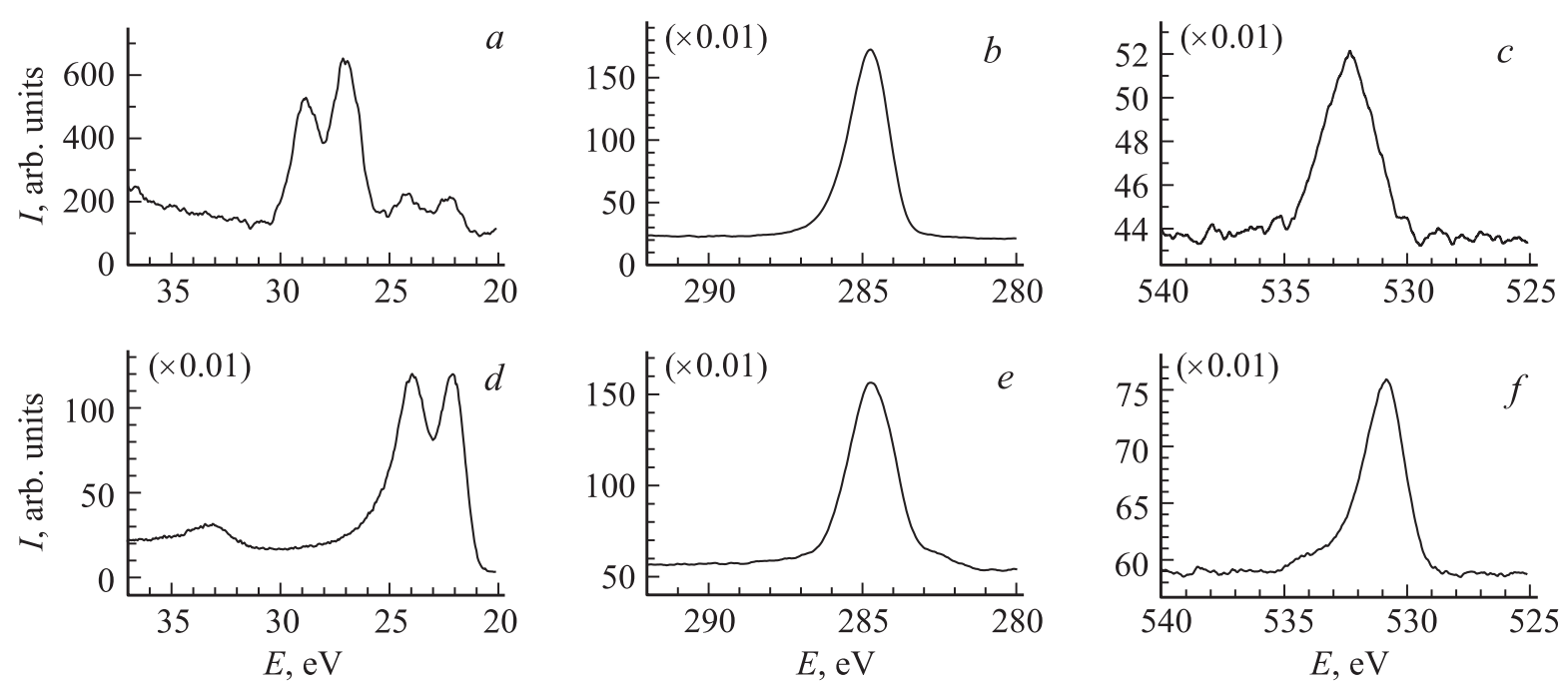

Рис. 3. Участки рентгеновских фотоэлектронных спектров в области максимумов атомных компонентов исследованных пленок GO на танталовой подложке. $a-c-$ максимумы $\mathrm{Ta}_{4 f}, \mathrm{C}_{1 s}$ и $\mathrm{O}_{1 s}$ соответственно образцов, приготовленных ex situ, $d-f-$ максимумы $\mathrm{Ta}_{4 f}, \mathrm{C}_{1 s}$ и $\mathrm{O}_{1 s}$ соответственно образцов после очистки посредством ионной бомбардировки. Значения интенсивности $I$ на частях $b-f$ уменьшены в 100 раз по сравнению с представленной на части $a$ для удобства сравнения. 

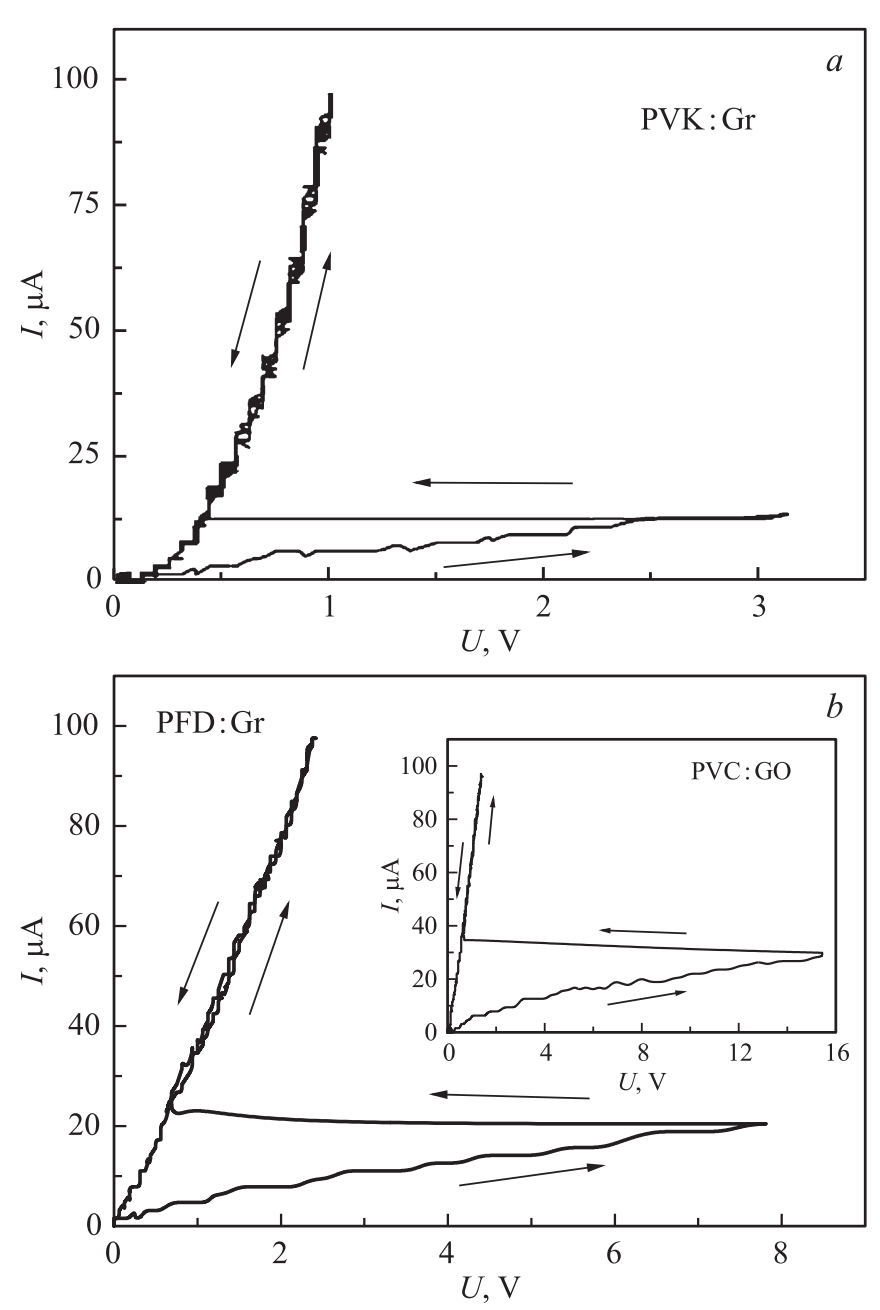

Рис. 4. ВАX композитных пленок Au/PVK: Gr/ITO/PET (a), $\mathrm{Au} / \mathrm{PFD}: \mathrm{Gr} / \mathrm{ITO} / \mathrm{PET}(b)$ при подаче треугольного импульса на электроды ITO-Au. На вставке - BAX Au/PVC: GO/ITO/PET при подаче треугольного импульса на электроды ITO-Au.

ного смещения. Как видно из рис. 4, для всех исследованных образцов ВАХ при увеличении напряжения имеют $S$-образный вид. Переход из НП- в ВП-состояние происходит при пороговых напряжениях $U_{T}$, различающихся по величине для разных типов полимерных пленок, при этом во всех случаях наблюдается резкое падение напряжения на образцах без существенного изменения протекающего через них тока, что может быть связано с эффектом шнурования тока [12]. Как следует из представленных результатов, пороговые напряжения переключения $U_{T}$ составляют $\sim 3-3.5, \sim 7-8$ и $\sim 15-16 \mathrm{~V}$ для композитных пленок PVK: Gr, PFD: Gr и PVC: GO соответственно. Сопротивление пленок после переключения меняется на порядок (т. е. в НП-состоянии сопротивление образцов составляет $\sim 200-500 \mathrm{k} \Omega$, а в ВП-состоянии $\sim 20-40 \mathrm{k} \Omega$ ). При уменьшении напряжения образцы, как правило, не возвращаются в НПсостояние, а остаются в ВП-состоянии. Как видно из рис. 4, $a$, BAX пленки $\mathrm{PVK}: \mathrm{Gr}$, находящейся в ВПсостоянии, имеет сверхлинейную зависимость в отличие от случаев пленок PFD: Gr и PVC: GO, где наблюдаются линейные $\mathrm{BAX}$. Изменения тока при переключении составляют $\sim 0.2 \mu \mathrm{A}$ для образца $\mathrm{PFD}: \mathrm{Gr}$ и $\sim 5 \mu \mathrm{A}$ для образца PVC: GO, в то время как для пленки PVK: Gr изменение тока равно нулю (с точностью до погрешности измерений). Возможно, наблюдаемые различия связаны с разными временами переключения образцов, которые составляют $\sim 20, \sim 30$ и $\sim 4 \mu$ s для пленок PFD:Gr, PVC: GO и PVK: Gr соответственно. В частности, время переключения пленки PVK: Gr при выбранном периоде тактовой частоты счетчика $1 \mu \mathrm{s}$ было оценено как $\sim 1 \mu \mathrm{s}$ (возможно, меньше $\sim$ сотни ns). Повторная подача импульсов той же или обратной полярности на образцы не приводит к обратному переключению в НП-состояние. Таким образом, в исследованных композитных пленках наблюдается эффект одноразовой WORM-памяти (write once read many).

Неустойчивости с $S$-образной ВАХ, наблюдаемые в пленках PVK:Gr и др., напоминают по своим характеристикам эффекты переключения, которые имеют место в халькогенидных стеклообразных полупроводниках (ХСП) [13]. Эффекты переключения подобного вида наблюдались также в ряде композитных пленок на основе полимеров с неорганическими частицами $\mathrm{Si}$ [14] и $\mathrm{ZnO}$ [15]. Согласно модели [16], в случае ХСП эффект неустойчивости тока обусловлен электронно-тепловыми явлениями, протекающими в пленке в сильных электрических полях. При этом для возникновения неустойчивости с $S$-образной ВАХ необходима положительная обратная связь, которая устанавливается между процессами нагрева и увеличения тока в материале с активационной температурной зависимостью проводимости $\sigma$ вида

$$
\sigma(T)=\sigma_{0} \exp (-\Delta E / k T)
$$

где $\Delta E-$ энергия активации проводимости, $k-$ постоянная Больцмана. Поскольку протекание тока вызывает нагрев образца, при наличии полупроводниковой зависимости $\sigma(T)$ вида (1) увеличение температуры вызывает возрастание проводимости, которое в свою очередь приводит к дальнейшему росту тока. Действие положительной обратной связи и возрастание температуры прекращаются при достижении температуры $T_{n}$, при которой $\left(\Delta E / k T_{n}\right)=1$ [17], что в структурах полупроводник-металл обусловлено достижением температуры фазового перехода. Подобные процессы характерны для некоторых видов ХСП, где при достижении температуры кристаллизации в области шнурования тока происходит фазовый переход стекло-кристалл, при этом в указанной области происходит переключение величины проводимости на несколько порядков: из НПсостояния (стекло) в ВП-состояние (кристалл) [16]. Отметим, что механизмы теплового шнурования тока, приводящие к $S$-образным ВАХ в других неорганических полупроводниках, были подробно рассмотрены в [18].

Электронно-тепловой механизм переключения может быть в определенной степени ответственным за $S$-образный вид ВАХ в исследуемых нами пленках на основе 
композитов полимеров с частицами Gr и GO. Однако в этом случае необходимо учитывать особенности термомеханических и электрических свойств полимеров, а также наличие окислительно-восстановительных процессов на частицах $\mathrm{Gr}$ и GO, внедренных в полимерную матрицу. Механические особенности полимеров заключаются в их способности находиться в стеклообразном, высокоэластичном и вязкотекучем состоянии. Рост проводимости с увеличением температуры, описываемый (1), характерен для стеклообразной (аморфной) фазы полимера. Переход полимера в высокоэластичное состояние, в котором проводимость не зависит от температуры и остается постоянной, происходит при достижении температуры стеклования $T_{g}$. При температуре плавления $T_{f}$ полимер переходит в вязкотекучее состояние, где также наблюдается увеличение проводимости с увеличением температуры [14]. Для исходных полимеров PVK и PVC температуры стеклования и плавления составляют $T_{g} \sim 200$ и $\sim 80^{\circ} \mathrm{C}$ и $T_{f} \sim 290$ и $\sim 270^{\circ} \mathrm{C}$ соответственно, при этом значения $T_{g}, T_{f}$ могут варьироваться в пределах $20-30^{\circ} \mathrm{C}$ в зависимости от толщины пленок и химического состава полимеров [19]. При температуpax выше $300 \mathrm{~K}$, как было показано для ХСП в [16], $S$-образные ВАХ и эффект переключения могут быть обусловлены эффектом шнурования тока через образец. Можно полагать, что при температурах $T>T_{f}$ полимер в области шнурования тока переходит в вязкотекучее состояние. При этом в данной области не происходит деструкции полимера, так как при высокой температуре из-за уменьшения на несколько порядков коэффициента вязкости происходит изменение надмолекулярной структуры полимера без нарушения его молекулярной структуры. После охлаждения области, в которой имело место шнурование тока, сопротивление образца может уменьшаться на порядок. Если бы температура области шнурования тока лежала в диапазоне $T_{g}<T<T_{f}$, т.е. в высокоэластичной фазе, где проводимость не зависит от температуры, то полимер после охлаждения возвращался бы в исходное НП-состояние, и ВП-состояние не сохранялось бы после снятия с образца электрического смещения.

На рис. 5 показана температурная зависимость удельного сопротивления $\rho(T)$ композитной пленки PVK: GO в структуре $\mathrm{Au} / \mathrm{PVK}: \mathrm{GO} / \mathrm{ITO} / \mathrm{PET}$, рассчитанная для омического режима BAX на постоянном токе при смещениях ниже напряжений переключения. Как видно из рис. 5, зависимость $\rho(T)=1 / \sigma(T)$ пленки PVK:GO имеет активационный характер с двумя характерными энергиями активации: $\Delta E \sim 16.4$ и $\sim 2.3 \mathrm{meV}$ для температур выше и ниже $200 \mathrm{~K}$ соответственно. Важно отметить, что значения $\Delta E$, полученные для композитных пленок PVK: GO как при $T>200 \mathrm{~K}$, так и при $T<200 \mathrm{~K}$, значительно меньше величин $\Delta E$, ожидаемых в рамках модели [16], разработанной для ХСП, а энергия активации $\Delta E \sim 16.4 \mathrm{meV}$ при $T>200 \mathrm{~K}$ сравнима с величиной $k T$ в этом температурном интервале. Мы полагаем, что наблюдаемые в пленках PVK: GO особенности

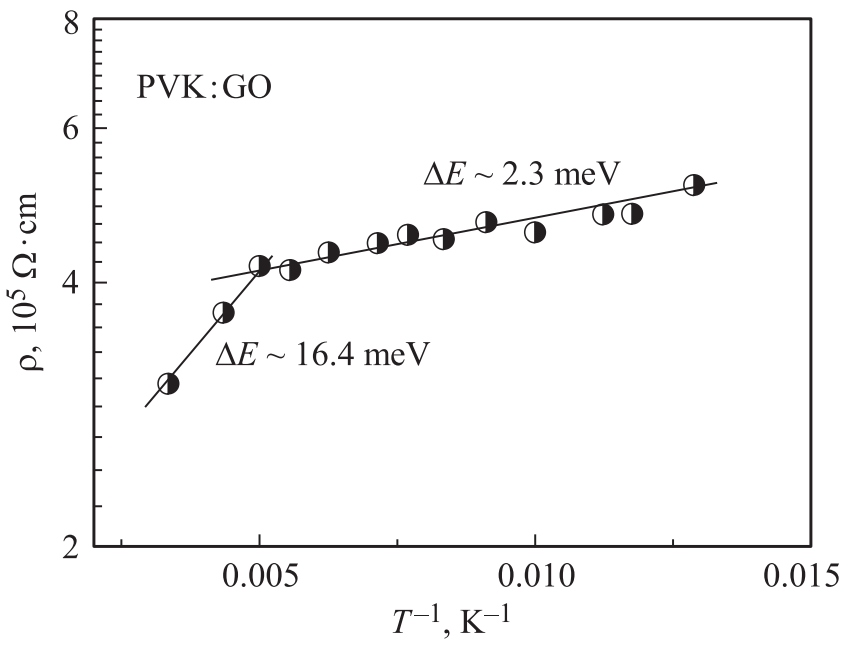

Рис. 5. Температурная зависимость удельного сопротивления пленки Au/PVK:GO/ITO/PET.

зависимости $\rho(T)$ и полученные малые значения $\Delta E$ могут быть обусловлены влиянием внедренных частиц $\mathrm{Gr}$ и GO на электронные свойства полимера-матрицы PVK.

На наш взгляд, эффект переключения в композитных пленках полимер PVK-частицы Gr и GO в значительной степени связан со структурными окислительновосстановительными процессами в частицах $\mathrm{Gr}$ и $\mathrm{GO}$, внедренных в матрицу полимера. Электронно-тепловые механизмы могут оказывать значительное дополнительное влияние на основные структурные процессы, определяющие эффекты переключения в таких композитах. Как было показано в работе [20], эффекты резистивного переключения в пленках чистого PVK происходят при напряжениях от $2 \mathrm{~V}$ и выше в зависимости от толщины пленки. В наших недавних работах [5,6] было установлено, что в пленках PVK-частицы Gr, GO переключение тока происходит при значительно меньших напряжениях $\sim 0.1-0.5 \mathrm{~V}$. Важно отметить, что эти величины напряжений коррелируют с потенциалами окисления и восстановления частиц $\mathrm{Gr}$ и $\mathrm{GO}$ в полимерной матрице PVK [5,6]. При восстановлении частиц Gr и GO имеет место преобладание $s p^{2}$-гибридизации над $s p^{3}$-гибридизацией, что означает возможность захвата большего числа носителей заряда такими частицами. Накопленный на частицах заряд создает большое локальное электрическое поле, которое ответственно за образование проводящего канала, проявляющегося, в том числе, и в эффекте шнурования тока через образец. Можно полагать, что именно структурные преобразования в частицах $\mathrm{Gr}$ и GO обусловливают формирование проводящего канала в полимерной матрице при существенно меньших напряжениях, чем в чистом PVK.

\section{4. Заключение}

Получены композитные пленки и исследован эффект резистивного переключения в структурах вида 
$\mathrm{Au} / \mathrm{PVK}(\mathrm{PFD} ; \mathrm{PVC}): \mathrm{Gr}(\mathrm{GO}) / \mathrm{ITO} / \mathrm{PET}$. Установлено, что в структурах $\mathrm{Au} / \mathrm{PVK}(\mathrm{PFD} ; \mathrm{PVC}): \mathrm{Gr}(\mathrm{GO}) / \mathrm{ITO} / \mathrm{PET}$ при подаче импульса напряжения наблюдается скачок проводимости, характеризующийся $S$-образными ВАХ и наличием их гистерезиса. Установлено, что время переключения тока в таких структурах составляет $t \sim 1-30 \mu \mathrm{s}$. Сделано предположение, что наблюдаемые эффекты связаны с влиянием окислительно-восстановительных реакций в композите с участием частиц Gr и GO, заключенных в матрицу полимера. При этом электроннотепловые механизмы могут оказывать дополнительное влияние на основные структурные процессы, определяющие эффекты переключения в таких композитах.

Авторы благодарны К.Д. Цэндину и Р.А. Сурису за полезные обсуждения.

\section{Список литературы}

[1] T.A. Skotheim, J.R. Reynolds. Handbook of conducting polymers. 3rd ed. CRC Press, NY. (2007). P. 620.

[2] C. Wu, F. Li, T. Guo, T.W. Kim. Org. Electron. 13, 178 (2012).

[3] W.-P. Lin, S.-J. Liu, T. Gong, Q. Zhao, W. Huang. Adv. Mater. 26, 570 (2014).

[4] J.R. Potts, D.R. Dreyer, C.W. Bielawski, R.S. Ruoff. Polymer 52, 5 (2011).

[5] П.С. Крылов, А.С. Берестенников, А.Н. Алешин, А.С. Комолов, И.П. Щербаков, В.Н. Петров, И.Н. Трапезникова. ФTT 57, 1639 (2015).

[6] A.N. Aleshin, P.S. Krylov, A.S. Berestennikov, I.P. Shcherbakov, V.N. Petrov, V.V. Kondratiev, S.N. Eliseeva. Synth. Met. 217, 7 (2016).

[7] A.N. Aleshin, I.P. Shcherbakov, A.S. Komolov, V.N. Petrov, I.N. Trapeznikova. Org. Electron. 16, 186 (2015).

[8] A. Ganguly, S. Sharma, P. Papakonstantinou, J. Hamilton. J. Phys. Chem. C 115, 17009 (2011).

[9] С.А. Фефелов, Л.П. Казакова, С.А. Козюхин, К.Д. Цэндин, Д. Арсова, В. Памукчиева. ЖТФ 84, 4, 80 (2014).

[10] J.F. Moulder, W.F. Stickle, P.E. Sobol, K. Bomben. In: Handbook of $X$-ray photoelectron spectroscopy. Ed. J. Chastain. 2nd ed. Perkin-Elmer Corporation (Physical Electronics), Eden Prairie (1992). P. 253.

[11] A.S. Komolov, K. Schaumburg, P.J. Møller, V.V. Monakhov. Appl. Surf. Sci. 142, 591 (1999).

[12] B.K. Ridley. Proc. Phys. Soc. 32, 954 (1963).

[13] S.R. Ovshinsky. Phys. Rev. Lett. 21, 1450 (1968).

[14] Э.А. Лебедев, Е.Л. Александрова, А.Н. Алешин. ФТТ 51, 195 (2009).

[15] Е.Л. Александрова, Э.А. Лебедев, Н.Н. Константинова, А.Н. Алешин. ФТТ 52, 393 (2010).

[16] К.Д. Цэндин, Э.А. Лебедев, А.Б. Шмелькин. ФТТ 47, 427 (2005).

[17] Б.Ю. Лотоцкий, Л.К. Чиркин. ФТТ 8, 1967 (1966).

[18] А.Ф. Волков, Ш.М. Коган. УФН 96, 633 (1968).

[19] B. Ellis, R. Smith. Polymers: a property database. 2nd ed. CRC Press (2008). 1052 p.

[20] S. Yanmei, A. Chunpeng, L. Junguo, L. Lei, W. Dianzhong, B. Xuduo. Thin Solid Films 598, 293 (2016). 